\title{
Thermal Calculation and Experimental Investigation of Electric Heating and Solid Thermal Storage System
}

\author{
Haichuan Zhao ${ }^{1}$, Ning Yan ${ }^{1, *}$, Zuoxia Xing ${ }^{1}$, Lei Chen ${ }^{1}$ and Libing Jiang ${ }^{2}$ \\ 1 School of Electrical Engineering, Shenyang University of Technology, Shenyang 110870, China; \\ zhaohaichuan123@sina.com (H.Z.); xingzuoxia1@sut.edu.cn (Z.X.); Chenleiyouxiang@sut.edu.cn (L.C.) \\ 2 Shenyang Lanhao New Energy Technology Company, Shenyang 110006, China; libingjiang@163.com \\ * Correspondence: yanning@sut.edu.cn; Tel.: +86-159-0982-6968
}

Received: 7 August 2020; Accepted: 2 October 2020; Published: 9 October 2020

\begin{abstract}
Electric heating and solid thermal storage systems (EHSTSSs) are widely used in clean district heating and to flexibly adjust combined heat and power (CHP) units. They represent an effective way to utilize renewable energy. Aiming at the thermal design calculation and experimental verification of EHSTSS, the thermal calculation and the heat transfer characteristics of an EHSTSS are investigated in this paper. Firstly, a thermal calculation method for the EHSTSS is proposed. The calculation flow and calculation method for key parameters of the heating system, heat storage system, heat exchange system and fan-circulating system in the EHSTSS are studied. Then, the instantaneous heat transfer characteristics of the thermal storage system (TSS) in the EHSTSS are analyzed, and the heat transfer process of ESS is simulated by the FLUENT 15 software. The uniform temperature distribution in the heat storage and release process of the TSS verifies the good heat transfer characteristics of the EHSTSS. Finally, an EHSTSS test verification platform is built and the historical operation data of the EHSTSS is analyzed. During the heating and release thermal process, the maximum temperature standard deviation of each temperature measurement point is $28.3^{\circ} \mathrm{C}$ and $59^{\circ} \mathrm{C}$, respectively. The correctness of the thermal calculation of the EHSTSS is thus verified.
\end{abstract}

Keywords: solid sensible heat storage; thermal calculation; fluid-solid coupling; heat transfer characteristics; experimental investigation

\section{Introduction}

In recent years, renewable energy utilization has developed rapidly in China. However, the abandonment of the renewable electricity generation is serious, especially during the wintertime heating period [1]. In the northern parts of China, CHP units are used for central heating in winter. The power output of CHP unit is greatly constrained by the heating load according to the principle of "power determined by heat" [2]. This has become one of the main reasons for the consumption of renewable energy in winter. The decoupling of the heat and power control of the CHP unit can be realized by adding a large amount of electric heating and heat storage unit to the $\mathrm{CHP}$ unit, which can effectively improve the adjustment capacity of the CHP unit and the renewable consumption capacity of the grid [3,4]. In addition, the traditional coal-fired boiler heating system for urban and factory thermal energy supply can also be replaced by the EHSTSS. It has become one of the effective ways to control air pollution. In the multi-energy system of combined cooling, heating and power, the thermal storage system can also be used as an energy storage system and a thermal energy supply system [5]. It can improve the diversity of thermal energy supply in a multi-energy system. In various thermal energy storage system, sensible heat storage is relatively popular because of its simple technology application and low cost [6]. More research on sensible heat storage heating systems mainly include the EHSTSS and the electrode boilers. Compared with the electrode boiler, the EHSTSS has advantages 
in heat storage density, safety, area covered and electrothermal response speed. It has become a research hotspot in recent years. The thermal calculation and the heat transfer characteristics analysis of the EHSTSS is a key link in the design and manufacture of the equipment. Similar to the thermal calculation of a traditional coal-fired boiler, the thermal calculation of the EHSTSS is mainly to calculate the key parameters of the equipment when the rated parameters are known [7].

Thermal energy storage (TES) is a technology under investigation since the early 1970s [8]. At present, the research on EHSTSS mainly focuses on the thermal storage medium, heat transfer characteristics of the system and structural optimization of the system. However, less attention has been paid to the thermal calculation of EHSTSS. Zhu et al. [9] report a helical-coil tube heat exchanger. The temperature difference of thermal energy storage is analyzed with and without considering radiative heat transfer. Gasia et al. [10] proposed a heat transfer enhancement technique that adds cheap and commercially available metallic wool. The thermodynamic performance of heat exchanger is analyzed from heat transfer process and enhancement of heat transfer characteristics in the above literature. However, only a single component is analyzed for thermodynamic performance, and the calculation method and process of heat exchanger thermal parameters are not investigated. Mousavi, et al. [11] investigated the melting process of phase change materials in an internal melt ice-on-coil thermal storage system. The effects of different operating parameters such as the inlet temperature and flow rate of the heat transfer fluid are analyzed, but there is no design calculation and heat transfer performance analysis of the heat storage module. Fadl et al. [12] present a latent heat thermal energy storage system. The influence of different heat transfer fluid inlet temperatures and volume flow rates of the system is evaluated by the experimental investigation. However, it lacks the heat exchanger parameter thermal design calculation process, and the optimization parameter curve of the overall system is not very obvious. In the aspect of TSS design, the existing research mainly focuses on the thermal calculation of parts of the TSS, such as separate heat exchangers, heat storage modules, etc. Raczka et al. [13] and Fujii et al. [14] introduced the design and calculation method of flue gas/waste water-heat exchanger and indirect heat exchanger, respectively. Du et al. [15] also reported a design method for heat storage units. However, the abovementioned research lacks any thermal design calculation of heat storage equipment from the perspective of a complete system and further systematic verification of equipment performance. It is necessary for the whole system as the research object to carry out thermal design calculation and systematic verification for EHSTSS.

Therefore, a systematic thermal calculation method for the EHSTSS is presented by this work. According to the structural characteristics of the system, thermal calculation of the system mainly calculates the parameters of the heating element, the TSS, the fan-circulating system and heat exchange system. Meanwhile, the fluid-solid coupling characteristics of the heat transfer in the TSS are analyzed. The numerical simulation of temperature distribution is carried out in the condition of heat storage and heat release. An experimental correlation for the EHSTSS is derived in order to verify correctness of the thermal calculation.

The two main contributions of this paper are summarized as follows:

- A thermal calculation process specifically designed for the EHSTSS is proposed.

- Systematic verification of the rationality and correctness of the EHSTSS from three aspects: case design, simulation analysis and experimental verification.

- The multi angle and systematic verification results can provide the basis for the optimal design of energy storage system.

The rest of this paper is organized as follows: Section 2 presents the thermal calculation method and process of the electric heating and heating storage system. Section 3 analyses the heat transfer characteristics of the TSS. Experimental verification is presented in Section 4. Section 5 concludes the paper. 


\section{Thermal Calculation Flow and Method of the EHSTSS}

\subsection{Thermal Calculation Flow of the EHSTSS}

The EHSTSS is composed of the TSS, including a thermal storage module and embedded heating element, the heat exchanger, the frequency converter fan, the thermal insulation layer, an external controller, etc. A structural diagram is shown in Figure 1. The overall dimensions of EHSTSS, i.e., length, width and height are $1560 \mathrm{~mm}, 720 \mathrm{~mm}$ and $1100 \mathrm{~mm}$, respectively. In the EHSTSS, the thermal storage unit uses a solid sensible thermal storage medium such as magnesium oxide. The length, width and height of the thermal storage unit are $240 \mathrm{~mm}, 115 \mathrm{~mm}$ and $53 \mathrm{~mm}$, respectively. The heating elements using $\mathrm{NiCr}$ or $\mathrm{FeCrAl}$ materials are embedded in the thermal storage module [16]. In the thermal storage process of EHSTSS, the thermal is generated by the heating element and stored in the thermal storage module. The thermal is extracted from the thermal storage module by the frequency conversion fan, and the thermal is exchanged through the heat exchanger to meet the heat load demand, when the heat load is in demand [17]. The heat transfer process mentioned above, the heat flow of the EHSTSS is mainly composed of heat generation, thermal storage, heat extraction and heat exchange. Therefore, taking heat flow and system structure into account, the EHSTSS is divided into heating system, thermal storage system, fan-circulating system and heat exchange system.

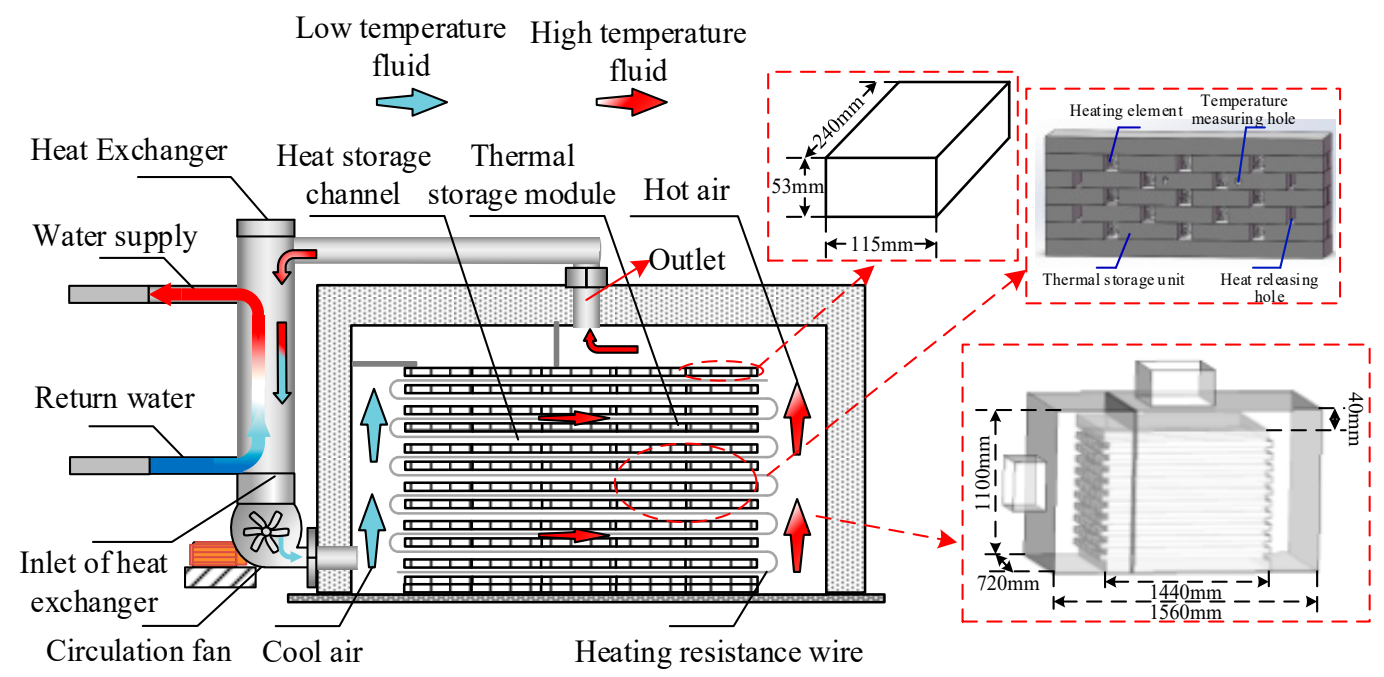

Figure 1. Structure diagram of the EHSTSS.

The four subsystems of the EHSTSS are interrelated. The thermal calculation of the EHSTSS should clarify the parameter relationship between the subsystems. The parametric relationship among the subsystems of the EHSTSS is shown in Figure 2.

Thermal calculation of EHSTSS usually start with thermal storage system. Before that, the key parameters of the EHSTSS need to be determined, mainly including thermal storage capacity, heating power, initial and final temperature of thermal storage module, temperature of supply and return water, heating time, heating voltage, etc.

Thermal calculation of the thermal storage system mainly determines the number of the thermal storage units and their arrangement. When the arrangement of thermal storage units is determined, the number of thermal storage channels and structure parameters of the TSS can be obtained. The number of thermal storage channels and structure parameters of the TSS are the vital input parameters of the heating system. The length and surface load of the heating element are calculated according to heating voltage, heating power, number of the thermal storage channel and other parameters. The parameter of the heat exchange system is affected by the maximum heat load, the temperature of upper and lower air ducts determined by the thermal storage system. The parameter 
of fan-circulating system is mainly affected by the air flow and the flow resistance which is determined by heat exchanger system and the thermal storage system.

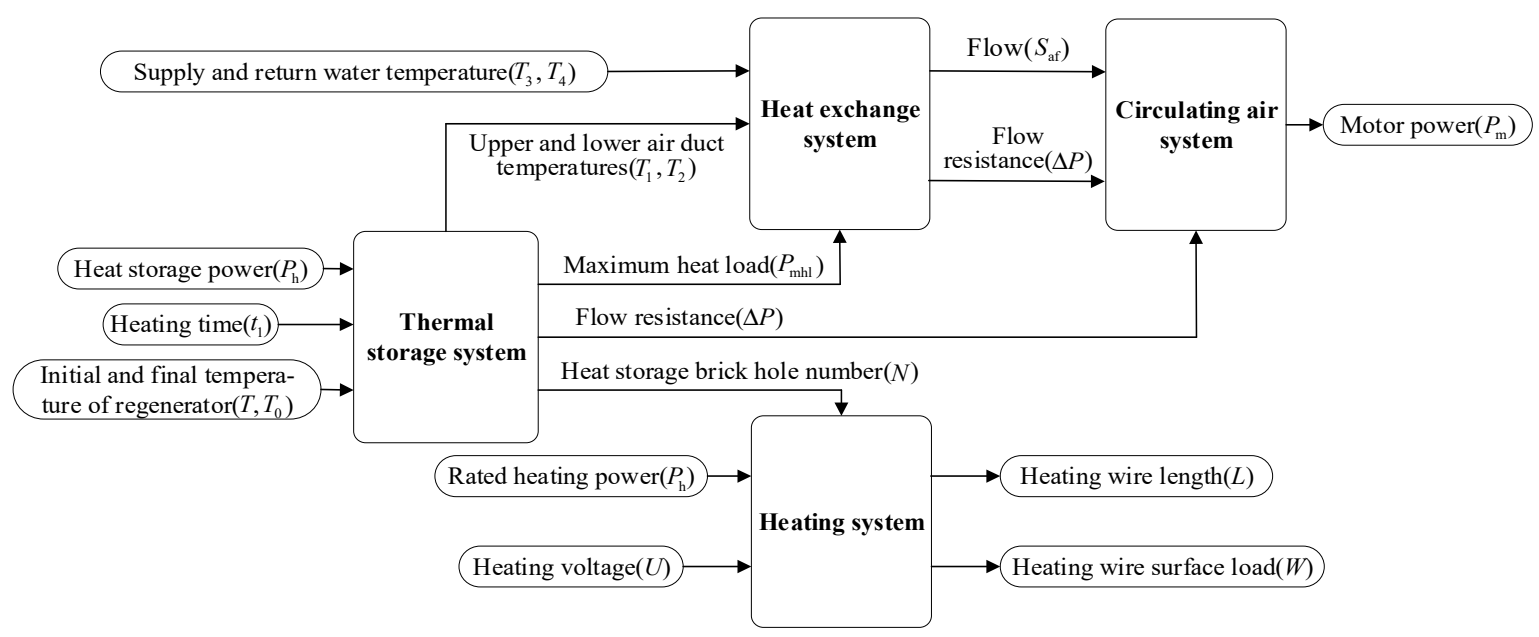

Figure 2. Thermal calculation relation of energy storage system.

The thermal calculation process for the four subsystem of the EHSTSS discussed above is shown in Figure 3. The calculation methods of key parameters in each subsystem are investigated below.

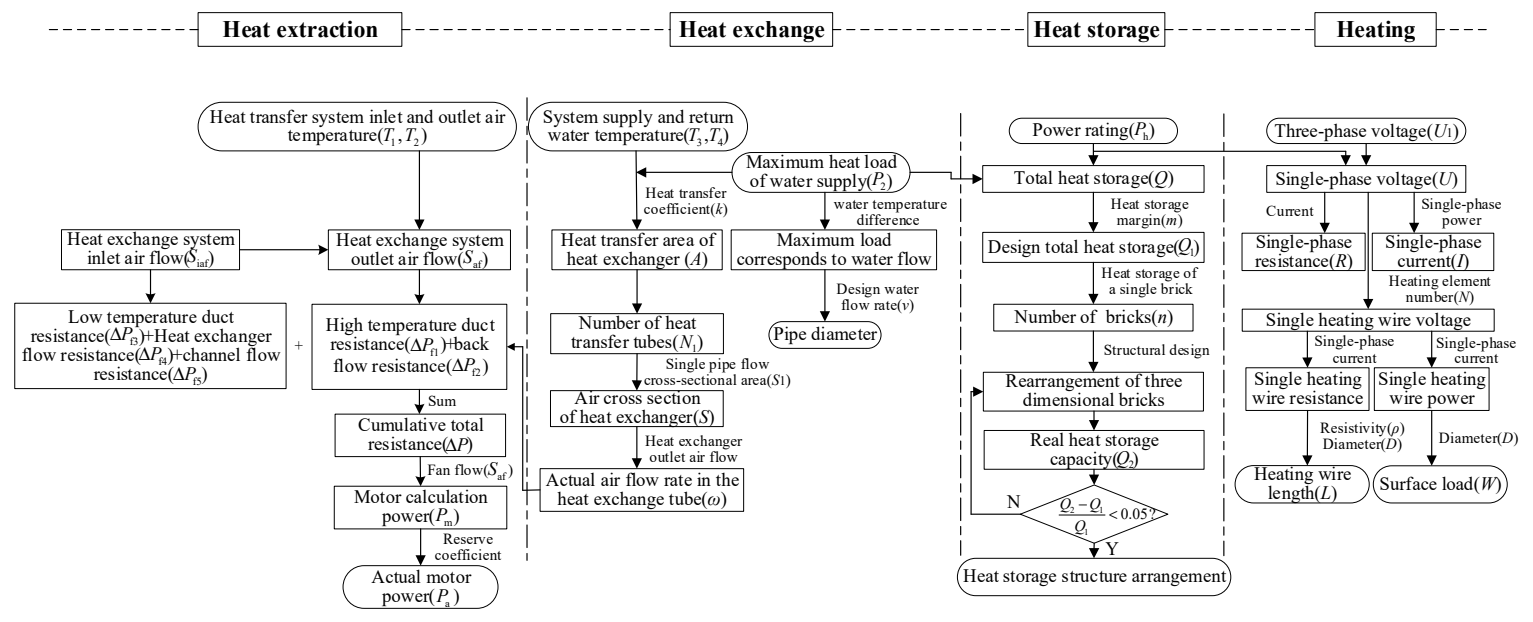

Figure 3. Thermal calculation flow diagram of solid thermal storage system.

\subsection{Thermal Calculation of Key Parameters of EHSTSS}

Thermal calculation is mainly aimed at calculating the key parameters in the four subsystems of the EHSTSS. The following is a detailed investigation to the calculation of key parameters in the subsystem.

\subsubsection{Thermal Calculation of Key Parameters in Heating System}

The heating power, the length of heating wire and the surface load of the heating element are the key parameters in the heating system. The heating power is the basic parameter of the heating system, which is mainly related to the building area, the thermal index of building heating and the heating time. The heating power $P_{\mathrm{h}}(\mathrm{kW})$ of the heating system can be determined by Equation (1):

$$
P_{\mathrm{h}}=\frac{24 P_{\mathrm{f}} F}{1000 t_{1} \eta}
$$


where $F$ represents heating area, $\mathrm{m}^{2} ; P_{\mathrm{f}}$ represents the value of heating index $\left(\mathrm{W} / \mathrm{m}^{2}\right)$ shown in Table 1 , $t_{1}$ represents heating time, $h ; \eta$ thermal efficiency of the system, thermal efficiency is the ratio of the thermal $Q_{1}$ generated by the heating element to the effective thermal $Q$ released by the system, i.e., $\eta=Q_{1} / Q$.

Table 1. Recommended value of heating index [18].

\begin{tabular}{cccccc}
\hline Type & Energy Saving & Non Energy Saving & Type & Energy Saving & Non Energy Saving \\
\hline Residence & $40 \sim 45$ & $58 \sim 64$ & Office & $50 \sim 70$ & $60 \sim 80$ \\
Hospital & $55 \sim 70$ & $65 \sim 80$ & Hostel & $50 \sim 60$ & $60 \sim 70$ \\
Store & $55 \sim 70$ & $65 \sim 80$ & Canteen & $100 \sim 130$ & $115 \sim 140$ \\
Cinema & $80 \sim 105$ & $95 \sim 115$ & Gym & $100 \sim 150$ & $115 \sim 165$ \\
\hline
\end{tabular}

When the physical parameters and diameter of the heated wire are determined, the length of the heating wire used for a single heating element is the key parameter related to the parameters such as heating voltage and heating power. The length $L$ of the heating wire can be expressed as follows:

$$
L=\frac{3 \pi U^{2} D^{2}}{4 k \rho_{\Omega} N P_{\mathrm{h}}}
$$

where $U$ represents the rated voltage, $\mathrm{V} ; \rho_{\Omega}$ represents the resistivity, $\mu \Omega \times \mathrm{m}, k$ represents a temperature coefficient, $N$ represents the heating element number, $D$ represents the diameter of the heated wire, $\mathrm{mm}$.

The surface load of the heating wire is the parameter that affects the service life of the heating element, so the rationality of the selection of the heating element can be judged according to the surface load. As the surface load increases, the temperature of heating element rises. In general, in high temperature heating applications, the surface load of heating elements can be controlled at $3 \sim 8 \mathrm{~W} / \mathrm{cm}^{2}$. The surface load $W$ of the heating wire can be expressed as follows:

$$
W=\frac{P_{\mathrm{h}}}{3 \pi L D}
$$

\subsubsection{Thermal Calculation of Key Parameters in Thermal Storage System}

In a thermal storage system, the key thermal calculation parameters are mainly the number and arrangement of thermal storage units. At the end of the preheating of the TSS, the average temperature is recorded as $T_{0}{ }^{\circ} \mathrm{C}$. When the thermal storage module is heated to a set temperature, the average temperature is $T^{\circ} \mathrm{C}$. When the physical and structural parameters of the thermal storage unit are known, the number $n$ of thermal storage units can be expressed as follows:

$$
n=\frac{m P_{\mathrm{h}} t_{1}}{\rho_{\mathrm{s}} C V\left(T-T_{0}\right)}
$$

where $C$ represents the thermal storage unit specific heat, $\mathrm{kJ} /\left(\mathrm{kg} \times{ }^{\circ} \mathrm{C}\right) ; \rho_{\mathrm{s}}$ represents the thermal storage unit density, $\mathrm{kg} / \mathrm{m}^{3} ; V$ represents the heat storage unit volume, $\mathrm{m}^{3}$ and $m$ represents the margin of thermal storage capacity.

According to the number of thermal storage units, the arrangement of TSS is calculated. The horizontal row number $a$ and the height row number $d$ of the thermal storage unit are determined, and the longitudinal row number $e$ can be expressed as follows:

$$
e=\left[\frac{Q}{a d \rho_{\mathrm{s}} C V\left(T-T_{0}\right)}+0.5\right]
$$

where $Q$ represents thermal storage capacity, $\mathrm{kWh} ; Q=m P_{1} t_{1}$. 


\subsubsection{Thermal Calculation of Key Parameters in Heat Exchange System}

The key parameters of the heat exchange system mainly include the heat transfer area, the number of heat exchange tubes and the air flow rate in the heat exchange tube.

In the heat exchanger, the heat transfer area of the heat exchanger is related to the heat transfer coefficient, the temperature difference of the fluid and the maximum heat load. The calculation of heat transfer area $A$ can refer to Equation (6):

$$
A=\frac{Q}{t_{2} \alpha \times \Delta T}
$$

where $\alpha$ represents heat transfer coefficient of heat exchanger; $t_{2}$ represents the fastest heat release time, $\mathrm{h}$; $\Delta t$ represents logarithmic temperature difference, ${ }^{\circ} \mathrm{C}$; which can be referred to Equation $(7)[19,20]$;

$$
\Delta T=\frac{\left(T_{2}-T_{3}\right)-\left(T_{1}-T_{4}\right)}{\ln \left[\left(T_{2}-T_{3}\right) / T_{1}-T_{4}\right]}
$$

where $T_{1}, T_{2}$ represents air temperature at inlet and outlet of heat exchanger, ${ }^{\circ} \mathrm{C} ; T_{3}, T_{4}$ represents the supply and return water temperature of the heat exchanger, ${ }^{\circ} \mathrm{C}$.

In Equation (6), the heat transfer coefficient $\alpha$ of heat exchanger can be expressed as:

$$
\alpha=0.023 \frac{\varepsilon}{D_{\mathrm{dl}}}\left(\frac{\omega D_{\mathrm{dl}}}{\mu}\right)^{0.8} \operatorname{Pr}^{0.4} \mathcal{C}_{\mathrm{t}} c_{1} \psi
$$

where $\varepsilon$ is the thermal conductivity at the average temperature of the air, $\mathrm{kW} /\left(\mathrm{m} \times{ }^{\circ} \mathrm{C}\right) ; \mu$ is the kinematic viscosity of air at average temperature, $\mathrm{m}^{2} / \mathrm{s} ; D_{\mathrm{dl}}$ is the outer diameter of the heat exchange tube, $\mathrm{m} ; \mathrm{Pr}$ is the Prandtl number of air at average temperature; $c_{\mathrm{t}}$ and $c_{1}$ are pipeline correction coefficients; $\psi$ is thermal efficiency coefficient.

The number of heat exchanger tubes is related to the heat transfer area, the length and diameter of the tubes. The length of the heat exchanger tube is suitable to the diameter, and the ratio of the tube length $\left(L_{1}\right)$ to the diameter $\left(D_{1}\right)$ is about 4 6 [19]. For the thermal calculation of the number of heat exchanger tubes we can refer to Equation (9):

$$
N_{1}=\frac{A}{\pi D_{1} L_{1}}
$$

where $N_{1}$ represents the number of heat exchanger tubes.

The flow resistance of heat exchanger accounts for a large proportion of the flow resistance of thermal storage system. The velocity of air in the tube is the key parameter affecting flow resistance.

In the heat exchange tube, the velocity of air under standard state can be expressed as follows:

$$
\omega_{0}=\frac{S_{\mathrm{af} 1}}{A_{1} \times 3600 \times 1.293}
$$

where $A_{1}$ represents cross-sectional area of heat exchange tubes, $\mathrm{m}^{2} ; S_{\mathrm{af} 1}$ is the air mass flow at the outlet of heat exchanger, $\mathrm{kg} / \mathrm{h}$; which can be expressed as:

$$
S_{\text {af1 }}=\frac{P_{\mathrm{h}} \times 3600}{C_{1} T_{1}-C_{2} T_{2}}
$$

where $C_{1}, C_{2}$ the specific heat of the air at the outlet and inlet of the heat exchanger, $\mathrm{kJ} /(\mathrm{kg} \times \mathrm{K})$.

The actual velocity of air in heat exchanger tube can be calculated as (12):

$$
\omega=\omega_{0}\left[\left(T_{1}+T_{2}\right)+273\right] / 273
$$




\subsubsection{Thermal Calculation of Key Parameters in Fan-circulating System}

In a fan-circulating system, the motor power of the frequency conversion fan is an extremely important parameter. The motor power is determined by the required flow resistance and flow. In the EHSTSS, flow resistance consists of two parts. One part is the high temperature channel flow resistance $\Delta P_{\mathrm{f} 1}(\mathrm{~Pa})$ and the back flow resistance $\Delta P_{\mathrm{f} 2}(\mathrm{~Pa})$ of heat exchange system, the other part is low temperature channel flow resistance $\Delta P_{\mathrm{f} 3}(\mathrm{~Pa})$, flow resistance $\Delta P_{\mathrm{f} 4}(\mathrm{~Pa})$ of the heat exchanger and the thermal storage channel flow resistance $\Delta P_{\mathrm{f} 5}(\mathrm{~Pa})$. The total resistance of the EHSTSS can be expressed as follows:

$$
\Delta P=\Delta P_{\mathrm{f} 1}+\Delta P_{\mathrm{f} 2}+\Delta P_{\mathrm{f} 3}+\Delta P_{\mathrm{f} 4}+\Delta P_{\mathrm{f} 5}
$$

where [21,22]:

$$
\begin{gathered}
\Delta P_{\mathrm{f} 1,2}=\frac{\lambda I \omega^{2} \rho_{\mathrm{a}}}{2 d e}\left(\frac{2}{\left(T_{\mathrm{w}} / T_{a v}\right)^{0.5}}+1\right)^{2} \\
\Delta P_{\mathrm{f} 3,4,5}=\frac{\lambda I \omega^{2} \rho_{\mathrm{a}}}{2 d e}
\end{gathered}
$$

where $\lambda$ represents friction coefficient in channel; $\rho_{2}$ represents medium density, $\mathrm{kg} / \mathrm{m}^{3} ; \omega$ represents air velocity, $\mathrm{m} / \mathrm{s}$; I represents length of channel, $\mathrm{m}$; de represents channel section equivalent diameter, $\mathrm{m} ; T_{\mathrm{w}}$ represents thermal storage unit surface average temperature, ${ }^{\circ} \mathrm{C} ; T_{\mathrm{av}}$ represents air average temperature, ${ }^{\circ} \mathrm{C}$.

The air volume flow $S_{a f}\left(\mathrm{~m}^{3} / \mathrm{h}\right)$ required for the fan-circulating system can be referred to Equation (16):

$$
S_{\mathrm{af}}=\frac{10.20 S_{\mathrm{af} 1}\left(T_{2}+273\right)}{273 \times 1.293}
$$

When the air pressure and air flow required for the fan-circulating system are determined, the motor power $P_{\mathrm{m}}(\mathrm{kW})$ can be calculated as follows:

$$
P_{\mathrm{m}}=\frac{1.1 \Delta P \times S_{\mathrm{af}}}{3600 \times 1020 \delta}
$$

where $\delta$ represents motor efficiency.

In order to verify the rationality and correctness of the thermal calculation process and method of the EHSTSS, the case design is based on the system with heating power of $100 \mathrm{~kW}$, daily thermal storage of $1 \mathrm{MWh}$ and heat transfer power of $125 \mathrm{~kW}$. The case design is shown in Appendix A.

\section{Analysis of Heat Transfer Characteristics of EHSTSS}

The heat transfer process of EHSTSS is a complex process which includes heat conduction, convective heat-transfer and radiation heat-transfer [23]. There are different heat transfer modes between structures of the system, as shown in Figure 4.

The operation process of EHSTSS is an alternating process between thermal storage and thermal release. The temperature of the TSS is a key index to judge whether design parameters of the system are suitable. Therefore, the heat transfer characteristics analysis of the system is carried out to explore the temperature variation rule of the heat storage device.

In the thermal storage process of an EHSTSS, heat transfer methods include convective heat-transfer between heating elements and cold air, radiation heat-transfer between heating elements and thermal storage module and heat conduction inside thermal storage module. In the thermal release process of the system, heat transfer methods include heat conduction inside thermal storage module and convective heat-transfer between cold air and thermal storage module. The heat transfer process in the system involves two regions of solid and fluid. Therefore, the analysis of the heat transfer characteristics between the two regions is of great significance to improve the heat storage efficiency of the heat storage module. 


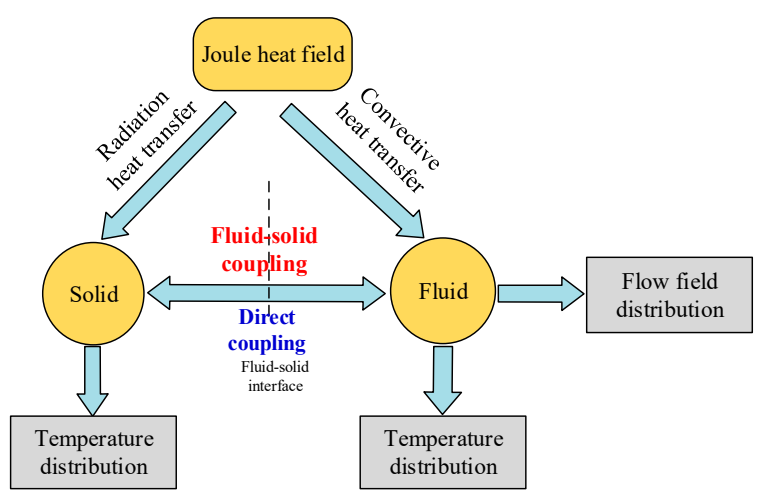

Figure 4. Flow-solid coupling diagram of solid thermal storage system.

\subsection{Heat Transfer Analysis in Thermal Storage Process}

The thermal in the thermal storage module is derived from the heating element. The thermal generated by the heating element interacts with the heat storage module through radiation heat exchange and convection heat exchange. The net heat $Q_{\mathrm{s}}$ in the thermal storage module can be expressed as follows:

$$
Q_{\mathrm{s}}=Q_{\mathrm{es}}+Q_{\mathrm{ea}}-Q_{\mathrm{a}}=C M_{\mathrm{s}}\left(T_{6}-T_{5}\right)
$$

where $Q_{\text {es }}$ represents radiant heat between heating element and thermal storage module, $\mathrm{W} ; Q_{\mathrm{ea}}$ represents convective heat between resistance element and air, $\mathrm{W} ; Q_{\mathrm{a}}$ represents heat carried by air, $\mathrm{W} ; M_{\mathrm{s}}$ is the weight of the heat storage module, $\mathrm{kg} ; T_{5}$ and $T_{6}$ represent initial temperature and temperature at any time of thermal storage module during heating, ${ }^{\circ} \mathrm{C}$.

The radiant heat $Q_{\text {es }}$ between the resistance element and the thermal storage module can be expressed as follows [24]:

$$
Q_{\mathrm{es}}=\beta\left[\left(\frac{T_{7}}{100}\right)^{4}-\left(\frac{T_{5}}{100}\right)^{4}\right] F_{1}
$$

where $T_{7}$ represents heating element temperature, ${ }^{\circ} \mathrm{C} ; \beta$ represents radiation coefficient, $F_{1}$ represents radiation surface area of heating element, $\mathrm{m}^{2}$.

For the convective heat $Q_{\text {ea }}$ between resistance element and air we can refer to Equation (20):

$$
Q_{\text {ea }}=\gamma\left(T_{7}-T_{1}\right) F_{2}
$$

where $\gamma$ represents convective heat transfer coefficient, $F_{2}$ represents heating wire area, $\mathrm{m}^{2}$.

The thermal $Q_{\mathrm{a}}$ carried by air can be written as:

$$
Q_{\mathrm{a}}=q_{m, \mathrm{~h}} V_{p, \mathrm{~h}}\left(T_{6}-T_{2}\right)
$$

where $q_{\mathrm{m}, \mathrm{h}}$ represents the mass velocity of the air, $\mathrm{m} / \mathrm{s} ; V_{p, \mathrm{~h}}$ represents the constant pressure specific volume of the air, $\mathrm{m}^{3}$. Applying Equations (19)-(21) into Equation (18) gives:

$$
T_{6}\left(C M_{\mathrm{s}}+q_{m, \mathrm{n}} V_{p, \mathrm{~h}}\right)=\beta\left[\left(\frac{T_{7}}{100}\right)^{4}-\left(\frac{T_{5}}{100}\right)^{4}\right]+\gamma F_{2} T_{7}-\gamma F_{2} T_{1}+q_{m, \mathrm{~h}} V_{p, \mathrm{~h}} T_{2}+C M_{\mathrm{s}} T_{5}
$$

The temperature $T_{6}$ of the thermal storage module at a certain moment can be calculated by Equation (22).

\subsection{Heat Transfer Analysis in Thermal Release Process}

In the thermal release process, the thermal source of the system is mainly the thermal storage module. The thermal released $Q_{\mathrm{r}}$ by the thermal storage module is equal to the sum of the effective 
thermal $Q_{c}$ and the lost thermal of the thermal storage system. The thermal released $Q_{\mathrm{r}}$ can be written as:

$$
Q_{\mathrm{r}}=Q_{\mathrm{c}} / \eta
$$

The thermal released $Q_{\mathrm{r}}$ also can be written as Equation (24) [24]:

$$
Q_{\mathrm{r}}=C M_{\mathrm{s}}\left(T_{8}-T_{9}\right)
$$

where $T_{8}$ and $T_{9}$ represent the initial temperature and the temperature at the moment of the thermal storage module during heat release, ${ }^{\circ} \mathrm{C}$. The effective heat released by the system can be expressed as Equation (25):

$$
Q_{\mathrm{c}}=M_{\mathrm{h}} C_{p . \mathrm{h}}\left(T_{3}-T_{4}\right)
$$

where $M_{\mathrm{h}}$ represents the mass flow rate, $\mathrm{kg} / \mathrm{s} ; c_{\mathrm{p} . \mathrm{h}}$ represents the specific heat, $\mathrm{kJ} /(\mathrm{kg} \times \mathrm{K})$.

Applying Equations (24) and (25) into Equation (23) gives:

$$
T_{9}=T_{8}-\frac{M_{\mathrm{h}} C_{p \cdot \mathrm{h}}\left(T_{3}-T_{4}\right)}{C M_{\mathrm{c}} \eta}
$$

The temperature $T_{9}$ of the thermal storage module at a certain moment can be solved by Equation (26).

\subsection{Simulation Results and Discussion}

\subsubsection{Parameters of Geometry Model}

According to the thermal calculation process and method of the EHSTSS proposed in the paper, the physical model of the TSS is built. The physical model parameters are set as shown in Table 2.

Table 2. Simulation parameters of the TSS.

\begin{tabular}{cc}
\hline Parameter Type & Value \\
\hline Thermal storage unit length, width and height & $240 \mathrm{~mm} \times 115 \mathrm{~mm} \times 53 \mathrm{~mm}$ \\
Thermal storage capacity $(\mathrm{MgO})$ & $1000 \mathrm{kWh}$ \\
Thermal storage unit specific heat & $960 \mathrm{~J} \cdot \mathrm{kg}-1 \cdot \mathrm{K}^{-1}$ \\
Bulk density & $2900 \mathrm{~kg} \cdot \mathrm{m}^{-3}$ \\
Heat transfer coefficient & $2.7 \mathrm{~W} \cdot \mathrm{m}^{-1} \cdot \mathrm{K}^{-1}$ \\
Initial temperature of thermal storage module & $380 \mathrm{~K}$ \\
Final temperature of heat storage module & $950 \mathrm{~K}$ \\
\hline
\end{tabular}

In order to measure the thermal storage module and fluid temperature in the system, six sets thermocouples are arranged to monitor the temperature of the thermal storage module and air in the channel as shown in Figure 5.

\subsubsection{Mathematical Model}

According to the previous analysis, the heat storage system is mainly divided into the fluid region formed by the incompressible high-temperature air and the solid region formed by the heat storage module. In the fluid region, the fluid heat transfer process can be described by three equations: the mass conservation equation, the momentum conservation equation and the energy conservation equation [25]. 


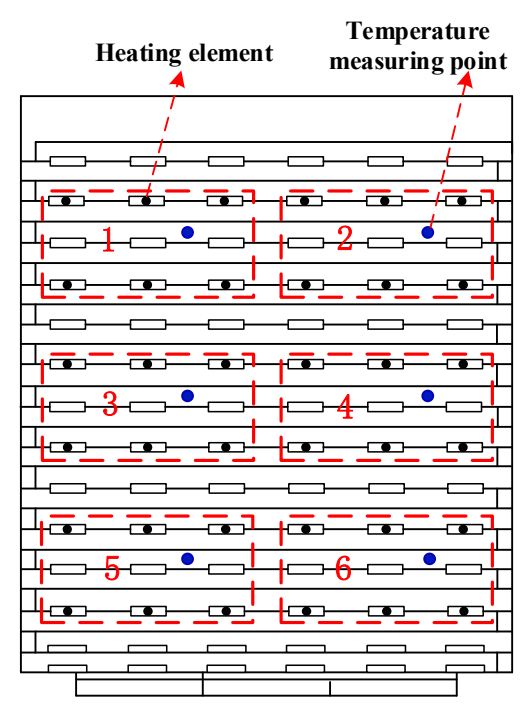

Figure 5. Thermocouple arrangement diagram (left view).

The mass conservation equation is:

$$
\frac{\partial \rho_{\mathrm{a}}}{\partial t}+\operatorname{div}\left(\rho_{\mathrm{a}} u_{\mathrm{j}}\right)=0
$$

The momentum conservation equation is:

$$
\rho_{\mathrm{a}} \frac{\mathrm{d} v}{\mathrm{~d} t}=\mathbf{F}-\nabla p+\xi \nabla^{2} v
$$

The energy conservation equation is:

$$
\rho_{\mathrm{a}} C_{p . h} \frac{\mathrm{d} T_{\mathrm{a}}}{\mathrm{d} t}=\nabla^{2}\left(\lambda_{\mathrm{a}} T_{\mathrm{a}}\right)+\phi+S_{i}
$$

where $T_{\mathrm{a}}$ is the air temperature in the thermal storage channel, $\mathrm{K} ; v$ is the air velocity in the thermal storage channel, $\mathrm{m} \cdot \mathrm{s}^{-1} ; \lambda_{\mathrm{a}}$ is the thermal conductivity of air, $\mathrm{W} \cdot \mathrm{m}^{-1} \cdot \mathrm{K}^{-1} ; \mathrm{F}$ is the mass force on the fluid, $\mathrm{N} ; p$ is the fluid pressure, $\mathrm{Pa}$; $\zeta$ is the dynamic viscosity of air, $\mathrm{kg} \cdot \mathrm{m}^{-1} \cdot \mathrm{s}^{-1} ; \phi$ is the loss equation; $t$ is the time, $\mathrm{s} ; S_{\mathrm{i}}$ is the energy source term. In this study, the energy source term is not considered, so $S_{\mathrm{i}}$ is set as 0 .

The heat storage module transfers energy by heat conduction. The heat conduction problem of the heat storage module can be simplified as a steady-state heat conduction problem. and its governing equation can be expressed as:

$$
\rho_{\mathrm{s}} C \frac{\partial T_{\mathrm{s}}}{\partial t}=\lambda_{\mathrm{s}}\left(\frac{\partial^{2} T_{\mathrm{s}}}{\partial^{2} x}+\frac{\partial^{2} T_{\mathrm{s}}}{\partial^{2} y}+\frac{\partial^{2} T_{\mathrm{s}}}{\partial^{2} z}\right)+S_{\mathrm{j}}
$$

where $\lambda_{\mathrm{s}}$ is the thermal conductivity of the thermal storage unit, $\mathrm{W} \cdot \mathrm{m}^{-1} \cdot \mathrm{K}^{-1} ; T_{\mathrm{s}}$ is the temperature of the thermal storage module, $\mathrm{K} ; x, y$ and $z$ are the coordinate values, $\mathrm{m} ; S_{\mathrm{j}}$ is the heating power per unit volume of the thermal storage module, $\mathrm{W}$.

On the thermal exchange interface between the high-temperature air and the thermal storage channel, the directly coupled fluid-solid interface must meet the energy continuity condition, that is, the temperature and heat flux density of the air and the heat storage channel are equal. It can be expressed as:

$$
\left\{\begin{array}{l}
T_{\mathrm{a}}=T_{\mathrm{s}} \\
q_{\mathrm{a}}=-\lambda_{\mathrm{a}}\left(\frac{\partial T_{\mathrm{a}}}{\partial \mathbf{n}}\right)=-\lambda_{\mathrm{s}}\left(\frac{\partial T_{\mathrm{s}}}{\partial \mathbf{n}}\right)=q_{\mathrm{s}}
\end{array}\right.
$$


where $q_{\mathrm{a}}$ is the heat flux density on the fluid side, $\mathrm{J} \cdot \mathrm{m}^{-2} \cdot \mathrm{s}^{-1} ; q_{\mathrm{s}}$ is the heat flux density on the solid side, $\mathrm{J} \cdot \mathrm{m}^{-2} \cdot \mathrm{s}^{-1} ; \mathbf{n}$ is the fluid-solid interface normal vector.

\subsubsection{Mesh Generation and Boundary Conditions}

The model was calculated using the commercial simulation software FLUENT15. The tetrahedral structured grid is used to divide the heat storage system. The grid division of heat storage system is shown in the Figure 6. The mesh irrelevance test is implemented under the 4 types of grid numbers. After the simulation process reaches the steady state, the results are shown in the Table 3. Compared with the high number of grids, there is a certain difference in the temperature simulation results when the number of grids is less than 1.06 million, and the simulation results change little when the number of grids exceeds 1.06 million. Therefore, the calculation speed and time is considered comprehensively, and the number of meshes is determined to be 1.06 million.

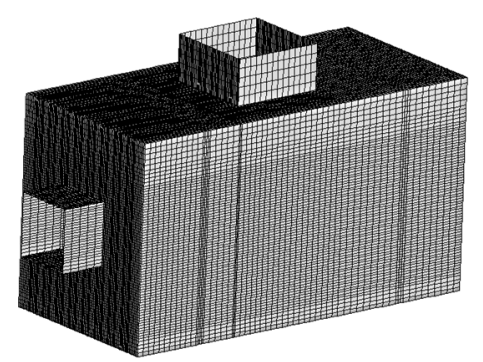

Figure 6. Grid division of heat storage system.

Table 3. Simulation results of the grid independence verification.

\begin{tabular}{ccccc}
\hline Porosity & Grid Type & $\begin{array}{c}\text { Number of } \\
\text { Grids/ Million }\end{array}$ & $\begin{array}{c}\text { Outlet Temperature of } \\
\text { Regenerator/K }\end{array}$ & $\begin{array}{c}\text { Core Temperature } \\
\text { of Regenerator/K }\end{array}$ \\
\hline \multirow{3}{*}{$15 \%$} & Structured & 1.06 & 648 & 688 \\
& hexagonal grid & 1.17 & 667 & 702 \\
& 1.28 & 669 & 704 \\
\hline
\end{tabular}

In the numerical simulation, time step is 10 . The air flowing in the heat storage channel and its front and rear cavities is a turbulent flow, and the $k-\varepsilon$ turbulence model is applied. The unsteady Reynolds time-averaged $\mathrm{N}-\mathrm{S}$ equation is used in simulation. The coupling between velocity and pressure is realized by SIMPLIC algorithm. The finite volume method is used to discretize the governing equations. The convection term difference scheme adopts the second-order upwind scheme. Dimensionless residuals of continuous equations reduced to less than $1 \times 10^{-3}$ are the convergence criteria.

Thermal storage: Heating power is $270 \mathrm{~kW}$. Absorption coefficient is 0.7. Cold air flow rate is $1 \mathrm{~m} / \mathrm{s}$. The outlet is set to the pressure outlet and the boundary condition of the wall is adiabatic and no slip. The interface between the fluid region and solid region is set as coupling interface. The total thermal storage time is $26.190 \mathrm{~s}$.

Thermal release: The heating power is set to $0 \mathrm{~kW}$. The inlet of cold air speed is $28 \mathrm{~m} / \mathrm{s}$ and air temperature is given according to field test data. Thermal release time is $41.130 \mathrm{~s}$.

\subsubsection{Simulation Results Analysis}

In the thermal storage process, the temperature variation of the TSS is shown in Figure 6. The temperature near the heating element is higher, and the temperature of the outlet section is more uniform. At the initial moment of heating, as shown in Figure $7 \mathrm{a}-\mathrm{c}$, the temperature at the inlet section emerges a peak, and the direction of the peak points to the inside of the thermal storage channel. It is caused by the difference of air velocity due to the accelerated flow of cold air inside the device 
and the uneven temperature distribution at the inlet of the heat storage channel. Because of the turbulence at the outlet of the thermal fluid, the temperature of the thermal fluid at the outlet of is lower. When the heating time reaches the set value, as shown in Figure $7 \mathrm{~d}$, the temperature of the thermal storage module is around $900 \mathrm{~K}$, and it reaches the preset temperature. Meanwhile, the heating element temperature is approximately $1100 \mathrm{~K}$, which is lower than the maximum temperature of the element. In conclusion, the temperature distribution of the thermal storage module is relatively uniform. The design and arrangement of the module and heating elements are reasonable, which verifies correctness of the thermal calculation of the system.

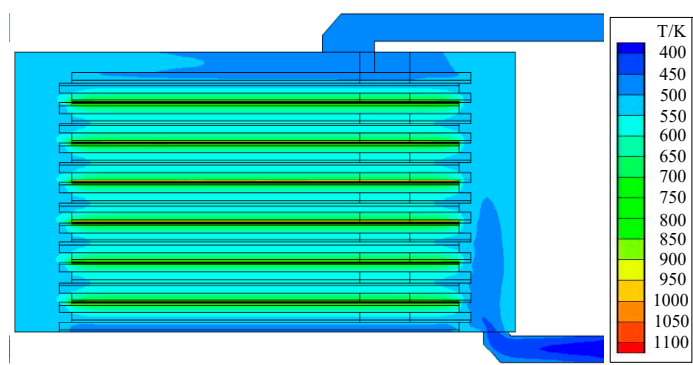

(a)

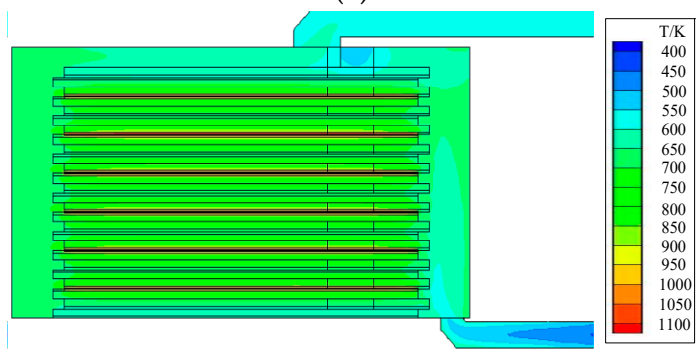

(c)

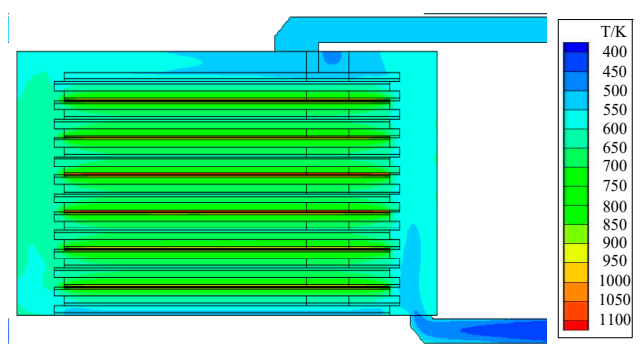

(b)

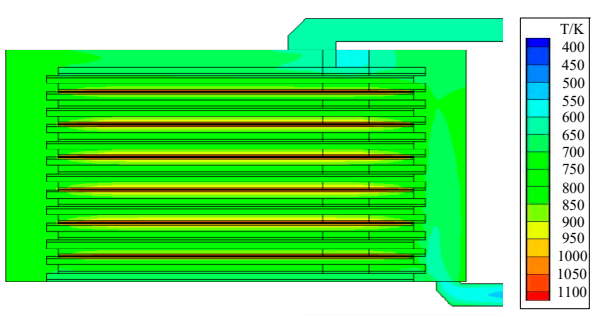

(d)

Figure 7. Cloud profile of temperature distribution at section during heating. (a) heat for $2 \mathrm{~h}$; (b) heat for $4 \mathrm{~h}$; (c) heat for $6 \mathrm{~h}$; (d) heat for $7.2 \mathrm{~h}$.

In the heat release process, the temperature distribution of the thermal storage module is shown in Figure 8. At the end of the thermal release, the temperature of module is uniformly distributed around $380 \mathrm{~K}$, which is consistent with the preset temperature. The temperature near the inlet is lower than other locations, which is caused by the rapid heat release due to the low air temperature and fast flow rate at the entrance. In conclusion, the TSS has a good match with air flow and velocity provided by the fan-circulating system, which makes the heat storage module complete the heat release within the setting time. The correctness and rationality of the thermal calculation and guidance for the EHSTSS is proved.

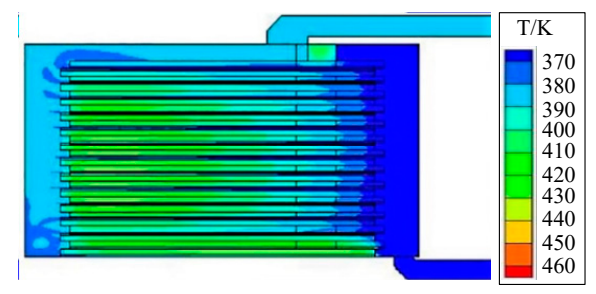

Figure 8. The temperature distribution of the system after the end of the thermal release.

\section{Experimental Results and Discussion}

In the paper, the operating data of the EHSTSS with a rated power of $125 \mathrm{~kW}$ in Anshan City, (Liaoning Province, China) are extracted and processed. The external and internal structure of 
the experimental equipment is shown in Figure 9. The heating area of the equipment is $1000 \mathrm{~m}^{2}$. The average outdoor temperature in winter at the location of the equipment is $-0.2{ }^{\circ} \mathrm{C}$ and the heating time is 114 days. In order to make the temperature of the measuring point more accurate at the testing time, the temperature at the sampling time and the temperature at $20 \mathrm{~s}$ before and after the sampling are measured, and the average of the three values is taken as the temperature at this time. The control parameters of the device are adjusted to stabilize the various operating data of the equipment. The operation data of the device under stable conditions was used.
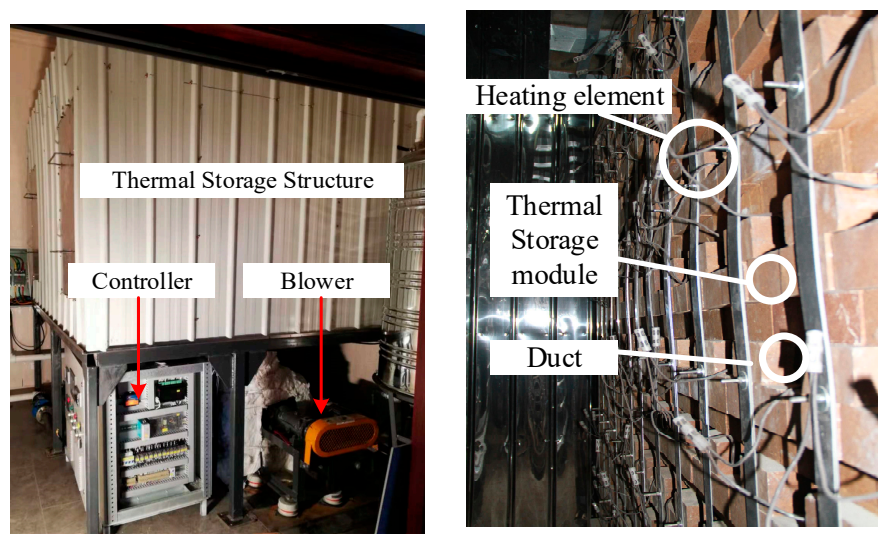

Figure 9. Experimental facility.

In the experiment, thermocouples are used to measure the temperature at different positions of the thermal storage module, and the positions the arrangement of thermocouples refer to in Figure 5.

\subsection{Analysis of Experimental Results Under Thermal Storage}

In the thermal storage process, temperature variation at each measuring point is shown in Figure 10. At the end of thermal storage, the temperature of measuring point 2 is the highest, and the temperature value is $715^{\circ} \mathrm{C}$. The lowest temperature was measured at point 4 , with a temperature value of $683^{\circ} \mathrm{C}$. The maximum temperature difference of the measuring point is $33^{\circ} \mathrm{C}$. The temperature standard deviation of each temperature measurement point at each moment is calculated, as shown by the dotted line in Figure 10a. In the middle of thermal storage, the temperature deviation at each point is relatively large, the maximum is $28.3^{\circ} \mathrm{C}$. At the beginning and end of thermal storage, the temperature deviation of the each point is small, only about $10^{\circ} \mathrm{C}$. Therefore, the temperature of the thermal storage module is relatively uniform, and the thermal stress of the thermal storage unit is smaller. The TSS design is reasonable.

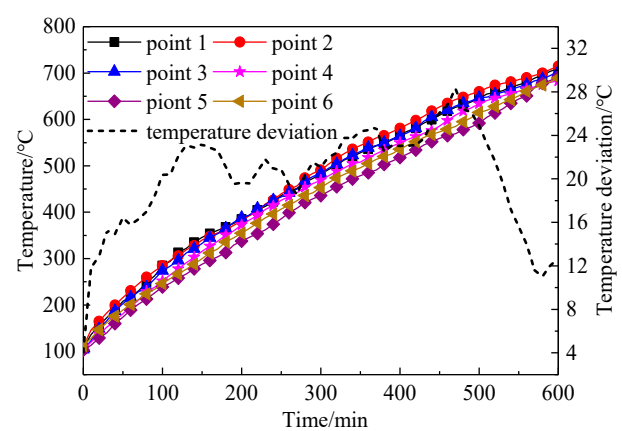

(a)

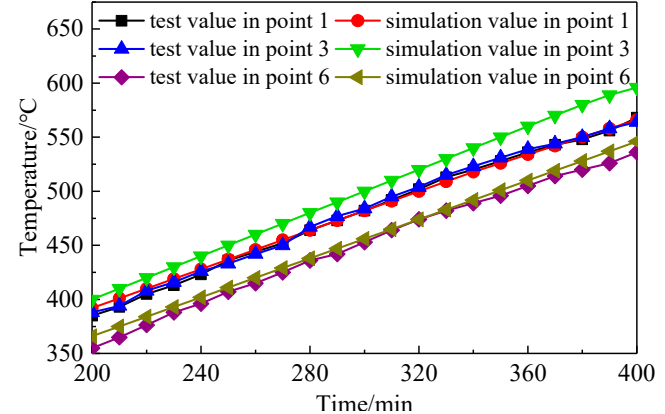

(b)

Figure 10. Temperature variation curves of measuring points of thermal storage module in the thermal storage process (a) experimental value and deviation of temperature at measuring point; (b) curve of test point temperature test value and simulation value. 
At the same time, the test value and simulation value of the temperature at measuring points 1, 3, and 6 are compared and analyzed, as shown in Figure 10b. The standard deviation statistics of the simulation value and the test value error rate of each measuring point are investigated, and the error deviations of the simulation value and the test value of the measuring points 1, 3, and 6 in the whole thermal storage process are respectively $0.796 \%, 0.925 \%$ and $0.805 \%$. The simulation value is close to the experimental value, so it can be seen that the EHSTSS designed in the paper has good heat transfer performance.

The average temperature curve of the thermal storage module in different typical working days is shown in Figure 11. The average temperature of the thermal storage module rises from $130{ }^{\circ} \mathrm{C}$ to about $700{ }^{\circ} \mathrm{C}$ during the heating time of $10 \mathrm{~h}$. The average temperature variation of the typical day has a small fluctuation, the temperature difference of the thermal storage module at the same time is small. The maximum temperature deviation is only $33.2^{\circ} \mathrm{C}$. It can be seen that the EHSTSS has good operational stability, and it can meet the design requirements.

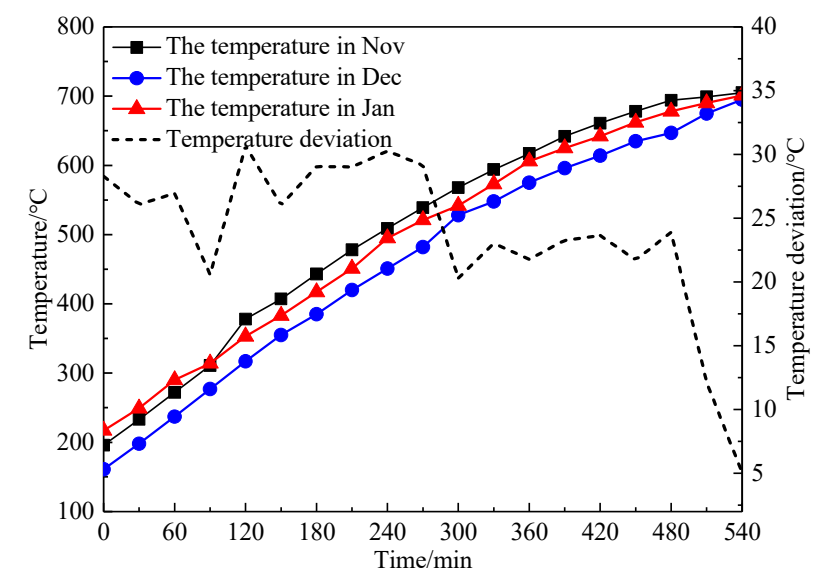

Figure 11. Temperature curve of the heat storage module under the heating.

The water supply temperature is constant as the control target. The average temperature of the TSS and frequency curve of the fan are shown in Figure 12. With the average temperature rising gradually in the preset range, the frequency of the fan declines, and the water supply temperature is maintained at the setting temperature about $50{ }^{\circ} \mathrm{C}$. It can be obtained that the parameters of heating system, thermal storage system, heat exchange system and fan-circulating system have good adaptability and compatibility. They ensure that the temperature change of the thermal storage module and the supply water can be stabilized in the set range.

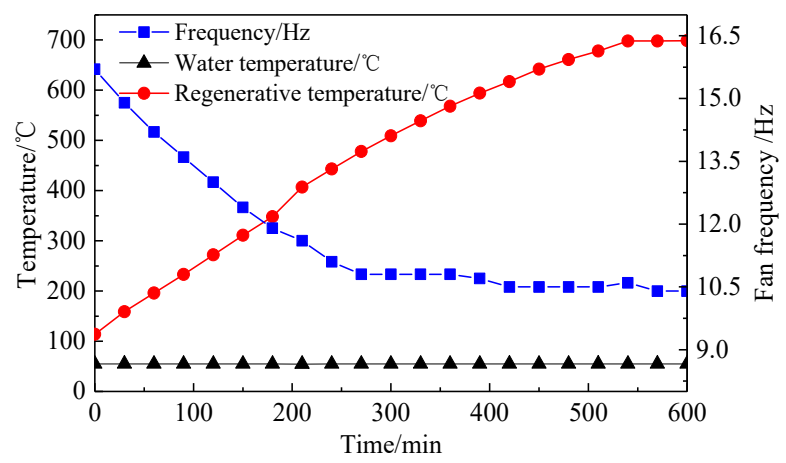

Figure 12. Supply water temperature, thermal storage module average temperature and fan frequency variation curve under thermal storage. 


\subsection{Analysis of Experimental Results Under Thermal Release}

In the thermal release process, temperature at each measuring point of the module is shown in Figure 13. At the end of thermal release, the temperature of measuring point 5 is the highest, and the temperature value is $121^{\circ} \mathrm{C}$. The lowest temperature was measured at point 3 , with a temperature value of $106^{\circ} \mathrm{C}$. The maximum temperature difference is $15^{\circ} \mathrm{C}$. The temperature standard deviation of each measuring point of the system at different times is analyzed. The maximum standard deviation of the system is $19.2^{\circ} \mathrm{C}$, and the temperature standard deviation of the system is maintained at about $10^{\circ} \mathrm{C}$ for most of the time. The thermal storage module of the system is proved to have good temperature uniformity, and the structure of thermal storage module is reasonable. The coordination between air circulation system and thermal storage system is good.

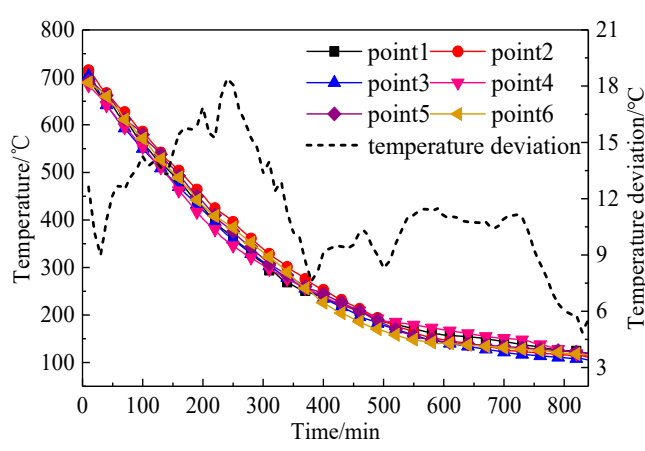

(a)

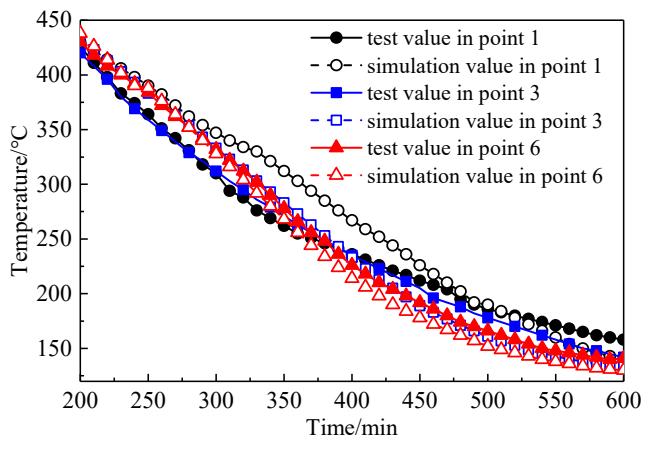

(b)

Figure 13. Temperature variation curves of measuring points of thermal storage module in the thermal release process (a) experimental value and deviation of temperature at measuring point; (b) curve of test point temperature test value and simulation value.

The test value and simulation value of the temperature at measuring points 1,3 , and 6 are compared and analyzed in the thermal release process, as shown in Figure 13b. The standard deviation statistics of the simulation value and the test value error rate of each measuring point are analyzed, and the error deviations of the simulation value and the test value of the measuring points 1,3 , and 6 in the whole thermal storage process are respectively $8.6 \%, 6.7 \%$ and $3.34 \%$. The simulated value has a certain deviation from the experimental value. This is mainly caused by the unavoidable heat leakage in the thermal insulation layer design during the experiment of the EHSTSS. Therefore, more attention should be paid to thermal insulation design in the system.

The average temperature variation curve of the thermal storage module on different typical working days is shown in Figure 14. The average temperature of thermal storage module on the typical daily varies from $700^{\circ} \mathrm{C}$ to $130{ }^{\circ} \mathrm{C}$ during the thermal release time of $14 \mathrm{~h}$. At the same time, the standard temperature deviation changes relatively large between each day, and the maximum temperature deviation reaches $59{ }^{\circ} \mathrm{C}$. Therefore, the operating fluctuation of the system during the heat release process is relatively large, and the system can be optimized from the angle of thermal release.

The water supply temperature is constant as the control target. The average temperature of the TSS and frequency curve of the fan are shown in Figure 15. The average temperature gradually decreases in the preset range. Meanwhile, the frequency of the blow rises. The temperature of the supply water still remains at a preset temperature of about $50{ }^{\circ} \mathrm{C}$. It can be concluded that the parameters of subsystem in the EHSTSS are reasonable, and each part has good compatibility with each other. Therefore, supply water temperature can be maintained stability by adjusting frequency of the fan to control the heat release. 


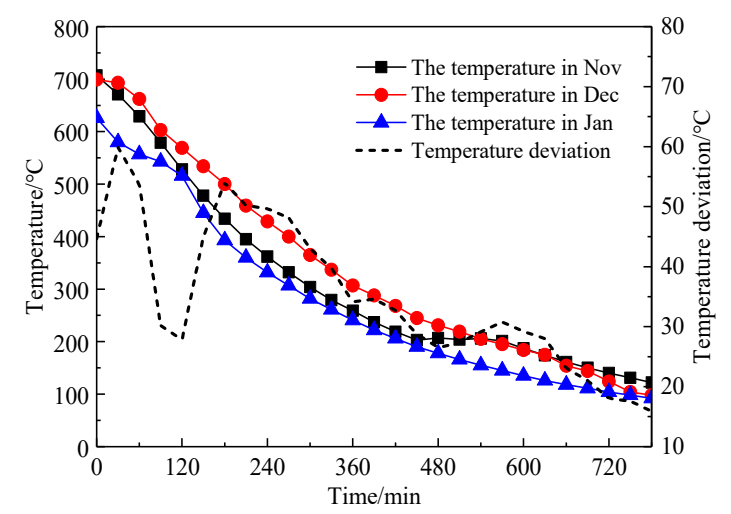

Figure 14. Average temperature curve of the module under thermal release process.

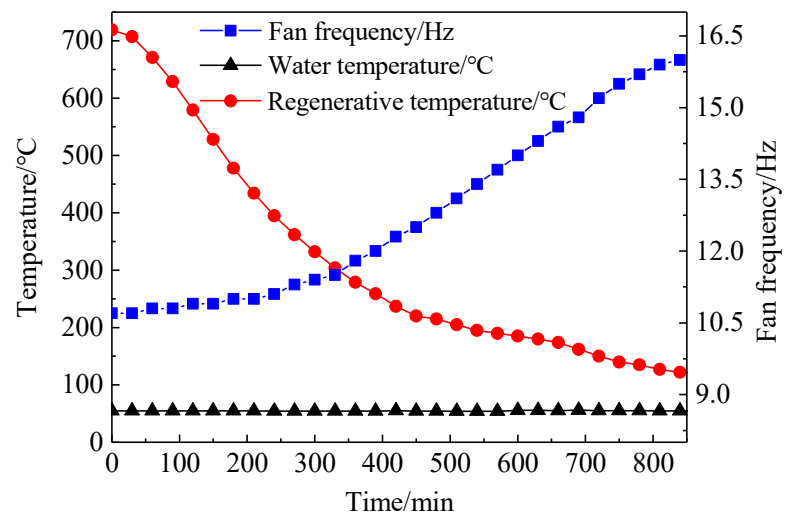

Figure 15. Supply water temperature, thermal storage module average temperature and fan frequency variation curve under thermal release.

\subsection{EHSTSS Electric Heating Characteristics and Pressure Drop Analysis}

The electrothermal conversion process of EHSTSS under operation condition is analyzed. The average temperature of each measuring point for the heat storage module and the power of EHSTSS are shown in Figure 16 within $72 \mathrm{~h}$. As shown in Figure 16 before the temperature of the heat storage module reaches the set value, the EHSTSS operates at full power to ensure that the system can store heat while outputting heat. After reaching the set temperature, in order to ensure that the temperature of the system is maintained at the set temperature before pure heat release, EHSTSS operates at half power. When the system is only exothermic, the power output of EHSTSS is stopped. The power output of EHSTSS changes periodically with the temperature of the heat storage module, which verifies that the system has good heat exchange and heat transfer performance.

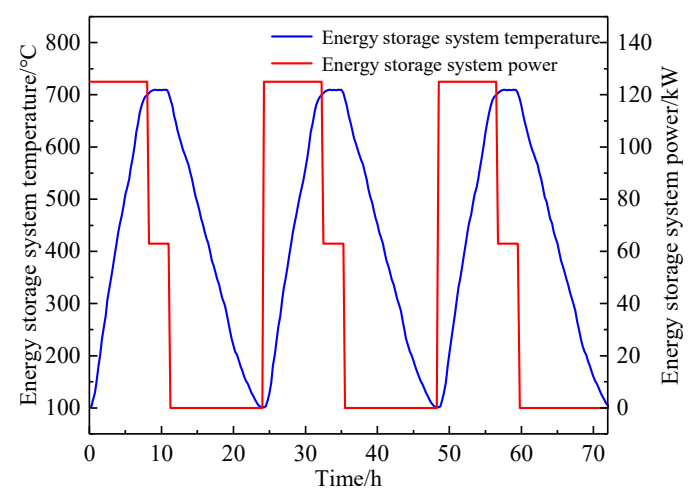

Figure 16. EHSTSS power-temperature curve in $72 \mathrm{~h}$ 
The pressure drop in the heat storage system under different wind speeds is tested by adjusting the speed of the hot air fan. The change curve is shown in Figure 17.

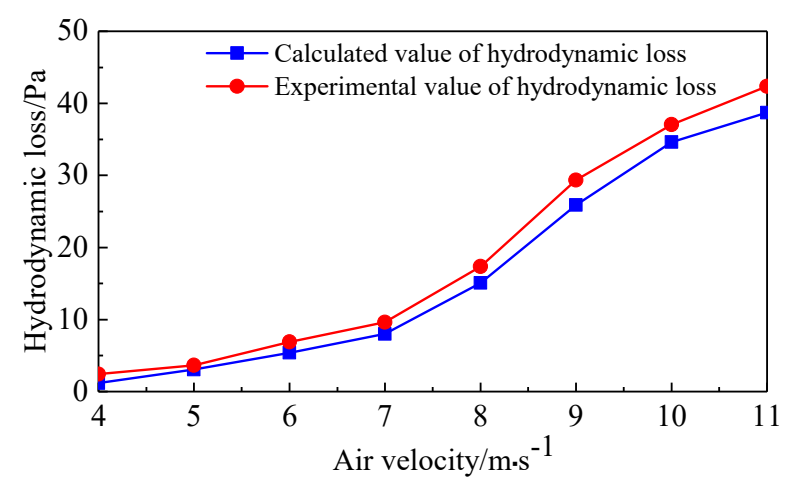

Figure 17. Variation curve of aerodynamic loss in the thermal storage system

As shown in Figure 17, the pressure drop of the heat storage system is $42.4 \mathrm{~Pa}$ at the rated wind speed of the fan, which is close to the calculated value $38.7 \mathrm{~Pa}$. At the same time, the calculated value of the pressure drop of the heat storage system at other wind speeds is also close to the test value. The rationality of fan selection and channel design is verified.

\section{Conclusions}

In the paper, the thermal calculation method and heat transfer characteristics of an EHSTSS is studied. The key parameters of the subsystems in the EHSTSS were investigated, and the feasibility of the proposed method was verified by a case design. The following conclusions are drawn through the actual case design, simulation analysis and experimental verification of the EHSTSS.

Systematic verification shows that within the rated heating and thermal release time, the internal thermal of the thermal storage module can be fully stored and released. The maximum temperature of the thermal storage module is controlled at about $700{ }^{\circ} \mathrm{C}$, and the outlet water temperature is stabilized at about $50{ }^{\circ} \mathrm{C}$. The design system can fully meet the design requirements.

During the heating process, the temperature gradient of each measuring point of the system is small. The maximum temperature standard deviation of each temperature measurement point at each moment is $28.3^{\circ} \mathrm{C}$. The simulation value is consistent with the test value, and error deviations of the temperature is only $0.796 \%, 0.925 \%$ and $0.805 \%$. The good heat transfer performance of the system is proved.

In the thermal release process, the temperature distribution of the system is uniform, and the temperature standard deviation of the system in each measuring point is maintained at about $10^{\circ} \mathrm{C}$ for most of the time. However, the standard temperature deviation changes relatively large between typical day in each month, and the maximum temperature deviation reaches $59^{\circ} \mathrm{C}$. This phenomenon indicates that there are some defects in the long-term operation stability of the system, which needs to be further improved. Corresponding parameter optimization can be made in terms of the number of channels of the heat storage module, the channel structure, and the location of the air inlet and outlet of the device.

From the perspective of case design, simulation analysis and experimental verification, the thermal calculation method, process and heat transfer characteristics analysis proposed in this paper are suitable for the design of an EHSTSS and it can provide a reference for the design and verification method of EHSTSS.

Author Contributions: All authors conceived and designed the study. H.Z. performed the experiment verification, the analysis of results and wrote the manuscript with guidance from N.Y., Z.X. and L.J., L.C. performed the simulation of the study. All authors have read and agreed to the published version of the manuscript. 
Funding: This work was supported by "The National Key Research and Development Program of China" (2017YFB0902100).

Conflicts of Interest: The authors declare no conflict of interest.

\section{Appendix A}

Table A1. Parameter design results of EHSTSS case.

\begin{tabular}{|c|c|c|c|c|}
\hline & Name & Value & Name & Value \\
\hline \multirow{5}{*}{$\begin{array}{l}\text { Basic parameter } \\
\text { calculation }\end{array}$} & $\begin{array}{l}\text { Configuration of heating } \\
\text { power } / \mathrm{kW}\end{array}$ & 100 & $\begin{array}{l}\text { Enthalpy value of return } \\
\text { water } / \mathrm{kJ}^{\prime} \mathrm{kg}^{-1}\end{array}$ & 189 \\
\hline & Heating time/h & 10 & $\begin{array}{l}\text { Enthalpy value of supply } \\
\text { water } / \mathrm{kJ}^{\mathrm{k}} \mathrm{kg}^{-1}\end{array}$ & 231 \\
\hline & Maximum heat release time/h & 8 & Pipe diameter $/ \mathrm{mm}$ & 50 \\
\hline & Inlet temperature of water $/{ }^{\circ} \mathrm{C}$ & 45 & Maximum heating load/ kW & 125 \\
\hline & Outlet temperature of water $/{ }^{\circ} \mathrm{C}$ & 55 & Total thermal storage capacity $/ \mathrm{kW} \cdot \mathrm{h}$ & 1000 \\
\hline \multirow{6}{*}{$\begin{array}{l}\text { Calculation of } \\
\text { heating element } \\
\text { parameter }\end{array}$} & Design power $/ \mathrm{kW}$ & 100 & $\begin{array}{c}\text { Number of single phase heating } \\
\text { elements }\end{array}$ & 11 \\
\hline & Three-phase voltage/V & 400 & Single-phase voltage/ V & 231 \\
\hline & Total number of heating elements & 33 & $\begin{array}{l}\text { Resistance of heating element } \\
\text { (single) } / \Omega\end{array}$ & 0.57 \\
\hline & Diameter of heating elements/ $\mathrm{mm}$ & 3 & Heating power(single)/ kW & 0.74 \\
\hline & Temperature coefficient & 1.08 & Length of heating element/ mm & 2474 \\
\hline & Resistivity $/ \Omega \cdot \mathrm{mm}^{-2} \cdot \mathrm{m}^{-1}$ & 4.79 & $\begin{array}{l}\text { Surface load of heating element/ } \\
\qquad \cdot \mathrm{cm}^{-2}\end{array}$ & 3.18 \\
\hline \multirow{8}{*}{$\begin{array}{l}\text { Calculation of } \\
\text { thermal storage } \\
\text { module } \\
\text { structure } \\
\text { design }\end{array}$} & Thermal storage margin & 1.1 & Total thermal storage capacity $/ \mathrm{kW} \cdot \mathrm{h}$ & 1100 \\
\hline & $\begin{array}{l}\text { Specific heat capacity of thermal } \\
\text { storage unit } / \mathrm{kJ} \cdot \mathrm{kg}^{-1} \cdot{ }^{\circ} \mathrm{C}^{-1}\end{array}$ & 1.064 & Volume of thermal storage unit $/ \mathrm{m}^{3}$ & 0.0041 \\
\hline & $\begin{array}{l}\text { Final average temperature of } \\
\text { thermal storage module } /{ }^{\circ} \mathrm{C}\end{array}$ & 700 & Weight of thermal storage unit/ $\mathrm{kg}$ & 11.55 \\
\hline & $\begin{array}{l}\text { Initial average temperature of } \\
\text { thermal storage module } /{ }^{\circ} \mathrm{C}\end{array}$ & 150 & $\begin{array}{c}\text { Design quantity of thermal storage } \\
\text { unit }\end{array}$ & 716 \\
\hline & $\begin{array}{l}\text { Horizontal row number of } \\
\text { thermal storage unit }\end{array}$ & 6 & Longitudinal row number & 7 \\
\hline & $\begin{array}{l}\text { Height row number of thermal } \\
\text { storage unit }\end{array}$ & 20 & Actual number of thermal storage unit & 724 \\
\hline & $\begin{array}{c}\text { Thermal storage unit } \\
\text { density } / \mathrm{kg} \cdot \mathrm{m}^{-3}\end{array}$ & 2800 & Weight of thermal storage module/ $\mathrm{kg}$ & 8357 \\
\hline & $\begin{array}{l}\text { Thermal storage capacity of } \\
\text { thermal storage unit/ } \mathrm{kW} \cdot \mathrm{h}\end{array}$ & 1.71 & Real thermal storage capacity/ $\mathrm{kW} \cdot \mathrm{h}$ & 1111 \\
\hline \multirow{4}{*}{$\begin{array}{l}\text { Calculation of } \\
\text { heat exchanger } \\
\text { selection }\end{array}$} & Design heat transfer load/ kW & 125 & $\begin{array}{l}\text { Outlet air flow of heat exchanger/ } \\
\qquad \mathrm{m}^{3} \cdot \mathrm{h}^{-1}\end{array}$ & 605 \\
\hline & $\begin{array}{l}\text { Inlet air temperature of heat } \\
\text { exchanger } /{ }^{\circ} \mathrm{C}\end{array}$ & 650 & $\begin{array}{l}\text { Inlet air flow of heat exchanger/ } \\
\qquad \mathrm{m}^{3} \cdot \mathrm{h}^{-1}\end{array}$ & 1967 \\
\hline & $\begin{array}{l}\text { Outlet air temperature of heat } \\
\text { exchanger } /{ }^{\circ} \mathrm{C}\end{array}$ & 105 & Heat transfer area $/ \mathrm{m}^{2}$ & 115 \\
\hline & $\begin{array}{c}\text { Heat transfer } \\
\text { coefficient } / \mathrm{kW} \cdot \mathrm{m}^{-2} \cdot \mathrm{k}^{-1}\end{array}$ & 1.1 & $\begin{array}{l}\text { Heat transfer area of heat exchanger } \\
\text { pipe } / \mathrm{m}^{2}\end{array}$ & 0.503 \\
\hline \multirow{7}{*}{$\begin{array}{l}\text { Calculation of } \\
\text { frequency } \\
\text { conversion fan } \\
\text { selection }\end{array}$} & $\begin{array}{l}\text { Length of heat exchanger } \\
\text { tube } / \mathrm{mm}\end{array}$ & 1000 & Number of heat exchanger tubes & 5 \\
\hline & $\begin{array}{c}\text { Diameter of heat exchanger } \\
\text { tube } / \mathrm{mm}\end{array}$ & 25 & $\begin{array}{l}\text { Real air velocity in heat exchanger } \\
\text { tube } / \mathrm{m} \cdot \mathrm{s}^{-1}\end{array}$ & 27.26 \\
\hline & $\begin{array}{l}\text { Flow resistance of thermal storage } \\
\text { channel/Pa }\end{array}$ & 6 & Total flow resistance/ $\mathrm{Pa}$ & 20177 \\
\hline & $\begin{array}{c}\text { Flow resistance of heat } \\
\text { exchanger } / \mathrm{Pa}\end{array}$ & 19688 & $\begin{array}{l}\text { Outlet air flow of circulating fan/ } \\
\qquad \mathrm{m}^{3} \cdot \mathrm{h}^{-1}\end{array}$ & 1969 \\
\hline & $\begin{array}{l}\text { Flow resistance of low } \\
\text { temperature duct } / \mathrm{Pa}\end{array}$ & 11 & Motor efficiency & 0.75 \\
\hline & $\begin{array}{l}\text { Flow resistance of high } \\
\text { temperature duct } / \mathrm{Pa}\end{array}$ & 22 & $\begin{array}{c}\text { Calculation power of circulating } \\
\text { fan } / \mathrm{kW}\end{array}$ & 6.5 \\
\hline & $\begin{array}{l}\text { Flow resistance after heat } \\
\text { exchanger } / \mathrm{Pa}\end{array}$ & 450 & Real power of circulating fan $/ \mathrm{kW}$ & 7.5 \\
\hline
\end{tabular}




\section{References}

1. Wang, H.X.; Yang, J.Y.; Chen, Z.; Li, G.; Liang, J. Optimal dispatch based on prediction of distributed electric heating storages in combined electricity and heat networks. Appl. Energy 2020, 267, 1-10. [CrossRef]

2. Dai, Y.; Chen, L.; Min, Y.; Chen, Q.; Hu, K.; Hao, J.; Zhang, Y.; Xu, F. Dispatch model of combined heat and power plant considering heat transfer process. IEEE Trans. Sustain. Energy 2017, 8, 1225-1236. [CrossRef]

3. Takahiro, N.; Tomohiro, A. High-temperature latent heat storage technology to utilize energy of solar heat and industrial exhaust heat. Int. J. Energy Res. 2016, 41, 240-251.

4. Dai, Y.; Chen, L.; Min, Y.; Mancarella, P.; Chen, Q.; Hao, J.; Hu, K.; Xu, F. Integrated dispatch model for combined heat and power plant with phase-change thermal energy storage considering heat transfer process. IEEE Trans. Sustain. Energy 2018, 9, 1234-1243. [CrossRef]

5. Liu, B.; Meng, K.; Dong, Z.Y.; Wei, W. Optimal dispatch of coupled electricity and heat system with independent thermal energy storage. IEEE Trans. Power Syst. 2019, 34, 3250-3263. [CrossRef]

6. Liu, X.; Wu, J.; Jenkins, N.; Bagdanavicius, A. Combined analysis of electricity and heat networks. Appl. Energy 2016, 162, 1238-1250. [CrossRef]

7. Dai, Y.H.; Chen, L.; Min, Y.; Mancarella, P. A general model for thermal energy storage in combined heat and power dispatch considering heat transfer constraints. IEEE Trans. Sustain. Energy 2018, 9, 1518-1528. [CrossRef]

8. Fernandez, A.I.; Martinez, M.; Segarra, M.; Martorell, I.; Cabeza, L.F. Selection of materials with potential in sensible thermal energy storage. Sol. Energy Mater. Sol. Cells 2010, 94, 1723-1729. [CrossRef]

9. Zhu, Y.; Yuan, Y.; Zhang, C.; Xie, M.; Tan, H. Numerical study on heat transfer enhancement of thermal energy storage systems considering radiation of molten salt. Sol. Energy 2019, 183, 337-344. [CrossRef]

10. Mousavi, A.S.S.; Poncet, S.; Sedighi, K.; Mojtaba, A.D. Numerical modeling of the melting process in a shell and coil tube ice storage system for air-conditioning application. Appl. Sci. 2019, 9, 2726. [CrossRef]

11. Fadl, M.; Eames, P.C. An experimental investigation of the heat transfer and energy storage characteristics of a compact latent heat thermal energy storage system for domestic hot water applications. Energy 2019, 188, 1-13. [CrossRef]

12. Gasia, J.; Maldonado, J.M.; Galati, F.; Marilena, D.S. Experimental evaluation of the use of fins and metal wool as heat transfer enhancement techniques in a latent heat thermal energy storage system. Energy Convers. Manag. 2019, 184, 530-538. [CrossRef]

13. Raczka, P.; Kazimierz, W. Methods of thermal calculations for a condensing waste-heat exchanger. Chem. Process Eng. 2014, 35, 447-461. [CrossRef]

14. Fujii, S.; Horie, N.; Nakaibayashi, K.; Kanematsu, Y.; Kikuchi, Y.; Nakagaki, T. Design of zeolite boiler in thermochemical energy storage and transport system utilizing unused heat from sugar mill. Appl. Energy 2019, 238, 561-571. [CrossRef]

15. Du, Y.X.; Xiao, G.M.; Gui, Y.W.; Lei, L.; Zhang, L.N.; Yu, M.X. Study on heat transfer characteristics of phase-change energy storage unit for thermal management. Int. J. Thermophys. 2014, 35, 1577-1589. [CrossRef]

16. Barrios, G.; Huelsz, G.; Rechtman, R. Heat transfer and flow transitions of a thermal plume generated by a heating element on the enclosure bottom wall. Eur. J. Mech. B/Fluids 2019, 77, 17-24. [CrossRef]

17. Yu, G.J.; Yu, B.; Liang, Y.T.; Wang, M.; Joshi, Y.; Sun, D.L. A new general model for phase-change heat transfer of waxy crude oil during the ambient-induced cooling process. Numer. Heat Transf. Part A Appl. 2017, 71, 511-527. [CrossRef]

18. Design Code for City Heating Network: Industry standard of China CJJ 34-2010; China Building Industry Press: Beijing, China, 2010; No. CJJ 34-2010.

19. Kim, M.H.; Lee, Y.T.; Gim, J.; Awasthi, A.; Chung, J.D. New effective thermal conductivity model for the analysis of whole thermal storage tank. Int. J. Heat Mass Transf. 2019, 131, 1109-1116. [CrossRef]

20. Tumsa, T.Z.; Mun, T.Y.; Lee, U.; Yang, W. Effects of coal characteristics to performance of a highly efficient thermal power generation system based on pressurized oxy-fuel combustion. Int. J. Energy Res. 2016, 41, 127-138. [CrossRef]

21. Gautam, A.; Saini, R.P. Experimental investigation of heat transfer and fluid flow behavior of packed bed solar thermal energy storage system having spheres as packing element with pores. Sol. Energy 2020, 204, 530-541. [CrossRef] 
22. Xu, H.J.; Zhao, C.Y. Analytical considerations on optimization of cascaded heat transfer process for thermal storage system with principles of thermodynamics. Renew. Energy 2019, 132, 826-845. [CrossRef]

23. Guo, H.; Xu, Y.J.; Guo, C.; Chen, H.S.; Wang, Y.F.; Zheng, Y.; Ye, H. Thermodynamic analysis of packed bed thermal energy storage system. J. Therm. Sci. 2020, 29, 445-456. [CrossRef]

24. Mosaffaa, A.H.; Talati, F.; Basirat Tabrizib, H.; Rosenc, M.A. Analytical modeling of PCM solidification in a shell and tube finned thermal storage for air conditioning systems. Energy Build. 2012, 49, 356-361. [CrossRef]

25. Guo, D.C.; Liu, M.; Xie, L.Y.; Wang, J. Optimization in plate-fin safety structure of heat exchanger using genetic and Monte Carlo algorithm. Appl. Eng. 2014, 70, 341-349. [CrossRef]

C 2020 by the authors. Licensee MDPI, Basel, Switzerland. This article is an open access article distributed under the terms and conditions of the Creative Commons Attribution (CC BY) license (http://creativecommons.org/licenses/by/4.0/). 